NIPER-502

Distribution Category UC-122

\title{
IMPROVEMENT OF SWEEP EFFICIENCY AND MOBILITY CONTROL IN GAS FLOODING
}

\author{
Topical Report \\ NIPER--502 \\ By \\ DE91 002229 \\ Arden Strycker \\ Feliciano M. Llave
}

April 1991

Work Performed Under Cooperative Agreement No. DE-FC22-83FE60149

Prepared for

U.S. Department of Energy

Assistant Secretary for Fossil Energy

Jerry Casteel, Project Manager

Bartlesville Project Office

P.O. Box 1398

Bartlesville, OK 74005

Prepared by

IIT Research Institute

National Institute for Petroleum and Energy Research

P. O. Box 2128

Bartlesville, OK 74005 


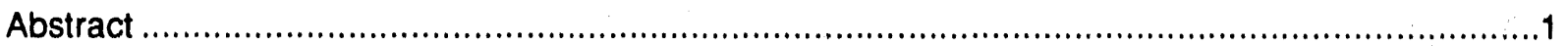

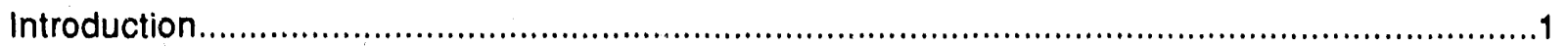

Evaluate Predictive Methods for $\mathrm{CO}_{2}$ Entrainer Systems ..........................................................

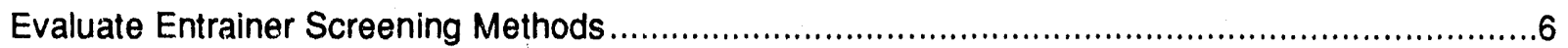

Mathematical Predictions Based on Theoretical Principles ...........................................6

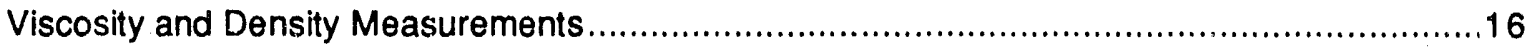

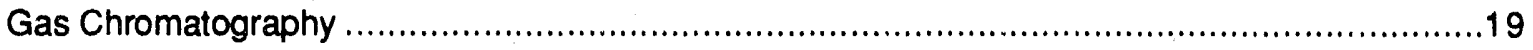

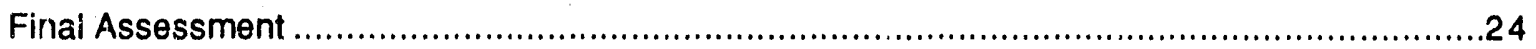

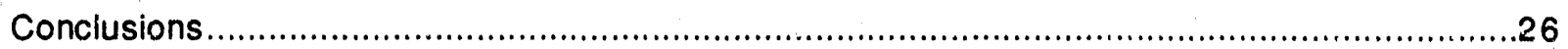

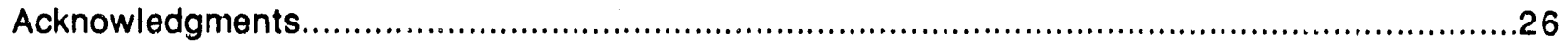

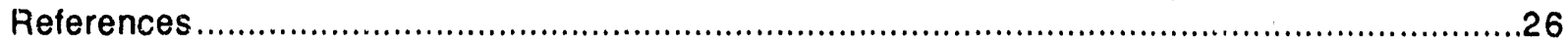

\section{TABLES}

1. Comparison of MMP factors for entrainer candidates with Wilmington crude oil.....................11

2. Rf values from GC analysis of various compounds on several hydrocarbon stationary phases

3. Comparison of entrainer-enhanced gas phase properties at $60^{\circ} \mathrm{C}$ and $2,200 \mathrm{psig}$

\section{ILLUSTRATIONS}

1. Experimental and predicted solubilities for naphthalene in supercritical carbon dioxide at $140.7^{\circ} \mathrm{F}$. .6

2. Estimation of MMP factor for a variety of hydrocarbons ...........................................14

3. Estimation of MMP factor for a variety of aromatic compounds .......................................14

4. Estimation of MMP Factor for a variety of alcohols....................................................15

5. Schematic diagram of entrainer capillary viscometer ................................................17

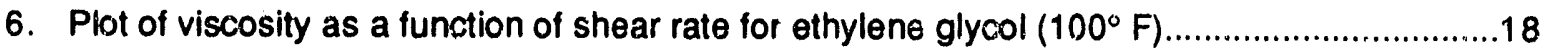

7. Comparison of viscosity for carbon dioxide and carbon dioxide plus ethylene glycol.............18

8. Retention indices of selected compounds on C25 GC column ...................................23 


\title{
IMPROVEMENT OF SWEEP EFFICIENCY AND \\ MOBILITY CONTROL IN GAS FLOODING
}

By Arden Strycker and Feliciano M. Llave

\begin{abstract}
The application of carbon dioxide or other gases to extract crude oil from depleted reservoirs has been shown to be a technically successful proce's. However, optimized recoveries are often compromised by poor sweep efficiencies because of low gas viscosities and densities. A new process was investigated that potentially could improve sweep efficiencies by enhancing extractability properties of the injected gas with entrainers. Use of a capillary viscometer to evaluate enhanced viscosities appeared to be the best procedure for evaluating candidate comfounds. A mathematical treatment was proposed based on predicting entrainer solubilities and minimum miscibility pressure alterations for carbon dioxide. However, use of many assumptions and approximations limited the effectiveness of this approach to qualitative evaluations. Some 87 compounds were evaluated using this mathematical treatment, and certain monoaromatic compounds were identified for further laboratory testing.

\section{INTRODUCTION}

The application of carbon dioxide to extract crude oil from depleted reservoirs has been shown to be a successful process. Although microscopic displacement efficiencies for carbon dioxide floods can be very high, sweep efficiencies are often low due to low viscosities and densities of carbon dioxide fluids. Carbon dioxide supercritical extraction of hydrocarbons is a major mechanism in miscible and immiscible floods. Several studies ${ }^{1-3}$ have reported that carbon dioxide extracis hydrocarbons in the $\mathrm{C}_{5}$ to $\mathrm{C}_{35}$ range. However, unfavorable mobilities and gravity segregation resulting from low viscosities and densities of the carbon dioxide phase often result in poor sweep efficiencies.

As stated in the U.S. Dept. of Energy's Oil Research Program Implementation Plan, ${ }^{4}$ the issues of mobility control, sweep improvement, and the lowering of miscibility pressure for carbon dioxide are of primary importance in engineering and extraction R\&D, the targeted and discipline-oriented supporting research for the national energy policy. The suggested highest priority class in the proposed plan is given as Open Shelf Platforms. The highest priority for mid-term supporting research for this class is "... on improving the application, sweep-efficiency, and project economics of carbon dioxide miscible flooding." The combined application of carbon dioxide miscible flooding and infill drilling with improved operation of secondary recovery projects has significant potential for substantially increasing oil recovery in complex carbonates of this type. 5
\end{abstract}


Several methods have been proposed to provide a solution to the mobility control problem: (1) water-alternating-gas (WAG) process; (2) use of surfactants to generate foam in order to retard gas mobility; (3) viscosifying the carbon dioxide rich phase by adding polymers as direct thickeners; ${ }^{6-7}$ (4) in situ polymerization of soluble monomers in supercritical carbon dioxide; ${ }^{8}$ and (5) viscosifying the carbon dioxide rich phase by adding entrainers. Results of research evaluating the use of entrainers to viscosify a carbon dioxide solution are summarized in this section of this report.

Supporting research on carbon dioxide entrainers for EOR is not currently being done by any other U.S. Dept. of Energy contractor and currently is not being extensively investigated by any other research group.

The concept of adding a small amount of a miscible; component to pure supercritical solvents in an effort to increase the solvent power of gases was first proposed by Peter et al. ${ }^{9}$ and Panzer. ${ }^{10}$ Their approach studied the effect of using benzene as an entrainer in the system propane-ethylene-stearic acid-oleic acid. The term "entrainer" was used by Panzer et al. ${ }^{11}$ to describe the improvement of the separation of a glyceride mixture using supercritical carbon dioxide in the presence of a liquid solvent additive. Brunner ${ }^{12}$ proposed three advantages for using entrainers: (1) the ability to improve the solubility of solutes of low volatility; (2) the possibility of modifying the PVT behavior of supercritical solvents; and (3) the ability to enhance selectivity when extracting a mixture. The increase in solvent power when adding cosolvents has also been noted in several recent publications. ${ }^{13-15}$

Several research groups have investigated the beneficial effects of additives for carbon dioxide flooding, although they have not called their additives entrainers. Stevens and Hawkins ${ }^{16}$ indicated that adding certain alcohols (ethylene glycol, n-hexanol, and n-butanol) could increase the viscosity of carbon dioxide. Although measurements reported in this report do not agiee with the values reported by Stevens and Hawkins, NIPER measurements have indicated that alcohols increase the viscosity of carbon dioxide. Hartman and $S h u^{17}$ indicated that certain additives can be added to carbon dioxide that improve the minimum miscibility pressure. They reported the results for $n$-butane as an additive. Kokolis ${ }^{18}$ discussed a similar idea using a light hydrocarbon solvent.

Cullick ${ }^{19}$ used entrainers in carbon dioxide to enhance the solubility of polymers. The polymers were added to carbon dioxide to enhance mobility control through increased viscosities. Djabbarah ${ }^{20}$ added an intermediate hydrocarbon such as tall oil to carbon dioxide to improve the mobility of the injected fluid. Finally, Irani ${ }^{21}$ added cosolvents to carbon dioxide and surfactants to improve the solvency and the mobility of the injected solution. Although some researchers have reported that adding certain compounds may enhance the mobility of carbon dioxide or other injected gases for EOR processes, no one has fully delineated the benefits of one class of compounds over another. Entrainer technology has not been sufficiently studied and documented to allow a producer to select the right entrainer for a particular reservoir, nor can a producer even select some 10 or 20 candidate compounds for further 
testing to identify the best entrainer. Results of research described in this report are a part of an on-going program at NIPER to develop this technology.

In the first section, results of foam studies conducted in FY90 are discussed. In the second section of this report, results from the entrainer studies conducted this year are discussed. Several aspects of the project are discussed, including development of screening techniques and development of predictive methods for entrainers. Although several compounds have been identified that provide beneficial properties, a more comprehensive study of all possible compounds has not been possible because of the time required to conduct the experimental measurements. Consequently, a more efficient screening procedure is needed. Toward that goal, available predictive methods were evaluated to determine if these methods might be useful in pre-screening coinpounds for study.

The Department of Energy has indicated that implementation of gas flooding EOR could have a major impact on domestic oil production in the near future. One factor that would have the greatest effect on increasing the degree of technical success for this process is developing economically successful methods to improve sweep efficiencies and to control the mobility of injected fluids. The studies described in this report were directed toward that goal.

\section{EVALUATE PREDICTIVE METHODS FOR $\mathrm{CO}_{2}$ ENTRAINER SYSTEMS}

For the entrainer technique development, it is essential to have a predictive model for the solubility of high-molecular-weight compounds (solid or liquid) in a gas at high pressure. An accurate predictive model could be used quickly to screen candidate entrainers and save time in conducting detailed experimental work. Considerable effort has been made by other researchers in modeling the supercritical extraction phenomena. Some progress has been made. This section summarizes currently available techniques in the prediction of solid or relatively nonvolatile liquid solubilities in a high-pressure gas. Thermodynamic models which have been applied to supercritical mixtures are separated into two approaches. One of these approaches is based on general phase equilibrium theory, and the other is based on fluctuation theory (Kirkwood-Buff solution theory).

The first approach is based on the thermodynamic relationship relating the fugacities $\left(f_{i}\right)$ of components $i$ in both equilibrium phases. For a binary solid-gas system, subscript 1 stands for the light (gaseous) component, and subscript 2 stands for the heavy (solid or nonvolatile liquid) component. The general equilibrium equation for component 2 is written as

$$
f_{2}^{s}=f_{2}^{v}
$$

where superscript $s$ stands for the solid phase, superscript $v$ for the vapor phase, and the solid phase is assumed to be pure. The solid phase fugacity of component 2 is given by 


$$
f_{2}^{s}=P_{2}^{s a t} \phi_{2}^{s a t} \exp \left(\frac{v \delta_{2}\left(P \cdot P_{2}^{s a t}\right)}{k T}\right)
$$

where $\mathrm{P}_{2}^{\text {sat }}$ is the saturation (vapor) pressure of the pure solid, $\phi_{2}^{\text {sat }}$ is the fugacity coefficient at saturation pressure $P_{2}^{s a t}$, and $v\{$ is the solid molar volume, all at temperature $T$. The vapor phase fugacity is

$$
f_{2}^{v}=y_{2} \$_{2} P
$$

Substituting equations 2 and 3 into equation 1, we obtain the solubility of the solid component in the gas phase at temperature $T$ and pressure $P$,

$$
y_{2}=\frac{P_{2}^{s a t} \phi_{2}^{s a t} \exp \left(v s\left(P-P_{2}^{s a t}\right) / k T\right)}{\phi_{2} P}
$$

or

$$
\ln (E)=\ln \left(\frac{y_{2} P}{P_{2}^{s a t}}\right)=\frac{v_{2}^{s}}{k T}\left(P \cdot P_{2}^{s a t}\right)-\ln \phi_{2}
$$

The enthancement factor, $E$, is the correction factor for the ideal gas expression, which is a measure of the extent to which pressure enhances the solubility of the solid in the gas. ${ }^{22}$ in equation 5 , we assume $\phi_{2}^{\text {sat }}=1$, since the pure-solid vapor pressures of interest are very low.

For $\mathrm{CO}_{2}$-hydrocarbon systems, the solubility of heavy component 2 in the vapor phase is given by

$$
y_{2}=\frac{x_{2} \gamma_{2} P_{2}^{s a t} \phi_{2}^{s a t} \exp \left(\int_{p_{2}^{s}}^{p} \frac{v \frac{1}{2} d p}{k T}\right)}{P_{\phi 2}}
$$

where $x_{2}$ is the mole fraction of component 2 in the liquid phase, and $\gamma_{2}$ is the activity coefficient for component 2, which is to account for the nonideality of the liquid mixture. ${ }^{22}$ Equation 6 can be simplified by setting $\phi_{2}^{\text {sat }}=1$ and $\gamma_{2}=1$, where the pure solute vapor pressure is very low and the liquid phase is assumed to be an ideal solution. Introduction of these assumptions yields a simplified equation:

$$
\ln (E)=\ln \left(\frac{y_{2} P}{P_{2}^{\text {sat }}}\right)=\ln x_{2}-\ln \phi_{2}+\frac{P v \frac{1}{2}}{k T}
$$

In equations 4 through 7 , the fugacity coefficient, $\phi 2$, can be calculated from any suitably accurate equation of state. However, most available equations of state are not accurate enough for the mixture properties in the critical region. Predicting the fugacity coefficient of the solute in the supercritical solvent 
from corresponding states theory based on critical properties of pure components is very difficult. Experimental data are usually required to determine the solute-solvent interaction constants in the equation-of-state; therefore, equations 4 through 7 are used only to model experimental results.

The second approach in predicting phase behavior of entrainer type systems is based on the Kirkwood-Buff solution theory. The expression for the solubility of solid in gas-phase at pressure $\mathrm{P}$ and temperature $T$ is given as: $23-24$

$$
\begin{aligned}
\ln (E)=\ln \left(\frac{y_{2} P}{P_{2}^{s a t}}\right)=\ln Z^{0}-\alpha_{12} \ln \left(\frac{\rho^{0}}{\rho^{0} \mathrm{kT}}\right) \\
+\left[V_{2}^{\delta}-\frac{1}{2}\left(V_{c, 1}+V_{c, 2}\right)+\alpha_{12} V_{c, 1}\right] \frac{\left(P-P_{2}^{s a t}\right)}{k T}
\end{aligned}
$$

where superscript o stands for pure gas properties, and subscript $c$ stands for the critical properties. Equation 8 involves only the solvent (gas) properties plus characterization parameters for the solute. To apply equation 8 , the molar volume of solute must be known at the respective values for $P, T$ and a scaling parameter, 0.12 , which is related with the Van der Waals attractive constant, aij.

$$
\alpha_{12}=\frac{a_{12}}{a_{22}}
$$

The parameter also can be estimated from the critical properties of both solvent and solute based on the conformal solution theory, 24

$$
\alpha \div 2=\frac{\left(V_{c, 1}+V_{c, 2}\right)}{2 V_{c, 1}} \sqrt{\frac{T_{c, 2}}{T_{c, 1}}}
$$

Since an accurate equation of state for $\mathrm{CO}_{2}$ properties has been developed, and since the critical property data or pure substances are available, equation 8 associated with equation 10 could be used to predict the solubility of high-molecular-weight compounds in supercritical $\mathrm{CO}_{2}$. An example is given for the $\mathrm{CO}_{2}$-naphthalene system in figure 1. Equation 8 adequately predicted the solute-solvent behavior for dilute solutions, but deviations from laboratory measurements increased with increasing solute concentration at higher pressures (higher pressures increase solute solubility). However, in general this approach for estimating solubilities is less reliable as the molecular weight of the solute is increased.

In conclusion, two approaches to estimating solubilities in supercritical carbon dioxide are available: estimation of solubility based on general phase equilibrium theory, and on fluciuation theory (KirkwoodBuff solution theory). Use of the Kirkwood-Buff solution theory appears to be the best currently available approach, although the accuracy is limited to dilute solutions. 


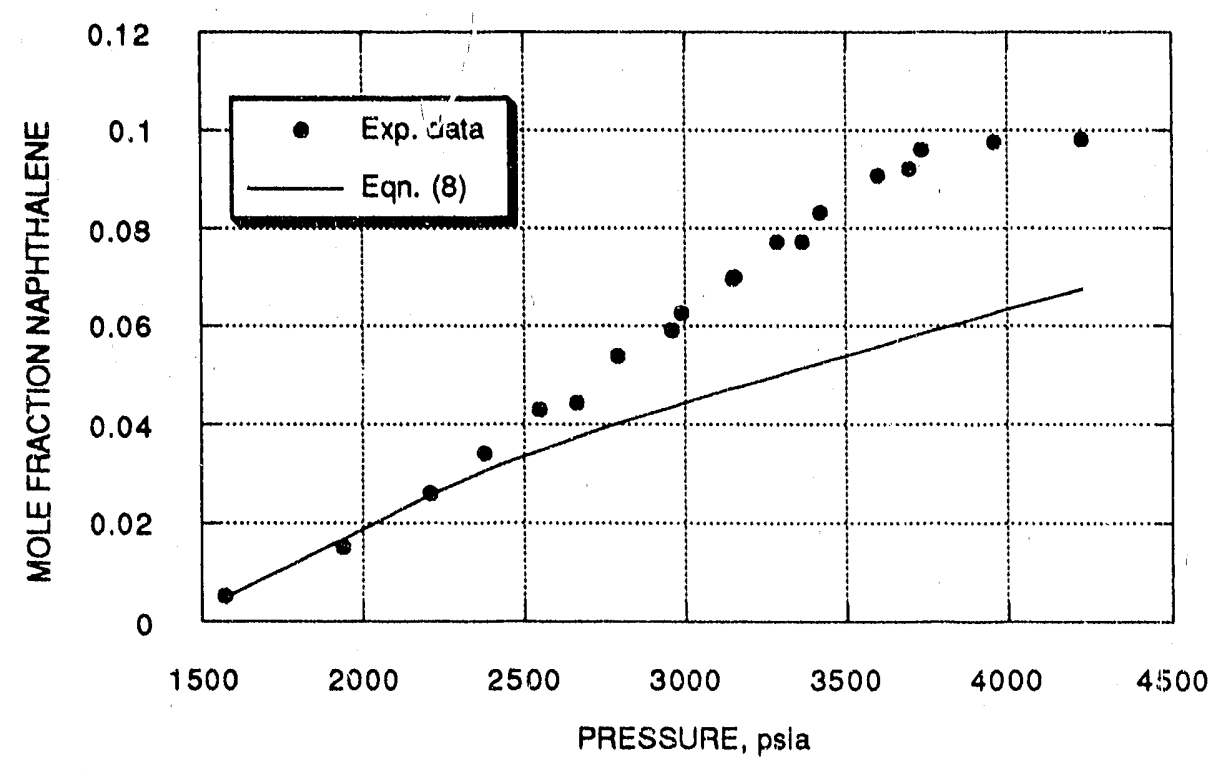

FIGURE 1. - Experimental and predicted solubilities for naphthalene in supercritical carbon dioxide at $140.7^{\circ} \mathrm{F}$. Experimental data from reference $25 ; \alpha_{12}=4.23$ from eq. 10 .

\section{EVALUATE ENTRAINER SCREENING METHODS}

Several studies conducted at NIPER have indicated that carbon dioxide entrainers can be effectively used to extract crude oll and enhance the sweep eificiency of the injected gas. However, to identify the best entrainer for a given set of conditions and crude oil, an efficient method for screening many candidates must be developed. At least two characteristics are sought for these screening methods: (1) the method should be relatively efficient in evaluating many compounds, and (2) results from the method should accurately reflect the relative performance of the tested compounds as entrainers for gas flooding. In addition to evaluating screening methods, evaluation of entrainers is also discussed.

A variety of methods was evaluated, and the results are described in this section. These methods include the use of gas chromatography, viscosity/density measurements, and predictions based on theoretical principles. Although coreflood experiments may be a more reliable method of evaluating entrainers, a considerable amount of time would be required to study each individual compound; therefore, conducting coreflood experiments was not considered as a viable screening tool. Each of the described methods evaluates certain properties considered relevant to the process.

\section{Mathematical Predictions Based On Theoretical Principles}

The most effective approach to screening compounds for EOR entrainers would be to utilize theoretical principles to develop mathematical predictors, and based on known physical properties of 
selected compounds, predict the best entrainers for a given set of conditions. Based on the current state of the art, this approach was evaluated for an arbitrarily selected set of conditions and crude oil.

In the previous section of this report, two approaches developed from theoretical principles were evaluated for their accurac; in estimating properties of carbon dioxide entrainer systems. Only equation 8 was considered accurate enough to provide a useful guide, and even for this approach serious errors may result due to the inability to predict accurately certain parameters. Recognizing the relative crudeness of this approach, a screening procedure was developed that did not involve any additional laboratory meas drements on our part.

The first assumption made in developing a screening method was that a carbon dioxide entrainer must be sufficiently soluble in carbon dioxide to minimize the effects of precipitation, adsorption, and partitioning processes. Solubilities were estimated using equation 8 and available information on critical parameters and vapor pressures. In addition, an entrainer should not be particularly soluble in water because of partitioning problems that would result. Solubility data from available literature were examined to eliminate those compounds that were found to have appreciable solubilities in water. Based on this approach, 87 compounds were selected for further evaluation.

The second assumption made in this screening approach was that enhancement of viscosity and density to the carbon dioxide fluid resulted from the coritribution of the entrainer and from the crude oil components that were extracted by the fluid system. Those entrainers that showed the greatest improvement in the extractability of crude oil components by carbon dioxide also would provide the greatest enhancement of viscosity and, therefore, mobility control. Although the contribution of viscosity enhancement by the entrainer itself is significant and should not be ignored, this enhancement will always be a direct function of the entrainer concentration. Because economics usually reward those systems requiring the least amount of additive, this second assumption presumes that the direct viscosity increase by an entrainer will be less significant than the viscosity increase resulting from the enhanced extractability of the overall fluid and the resulting contributions from crude oil components.

The third assumption made in this screening approach was that the enhancement of extractability of crude oil by the addition of entrainers results from a beneficial modification of the carbon dioxide hase behavior. Many studies on carbon dioxide phase behavior and how this behavior is modified by other components illustrate the importance of this relationship. Furthermore, supercritical carbon dioxide should not be thought of only as a liquid or as a gas, but some combination of both; therefore, basing evaluations of extractability on traditional solution ideas probablv will be ineffective because of the inherent differences of the two concepts. The previous section that evaluates predictive methods illustrates the difficulty that currently exists with known technology to predict phase behavior of such complicated systems as carbon dioxide-water-entrainer-crude oil.

Consequently, another simplifying approach was made in the screening procedure. Measuring the minimum miscibility pressure (MMP) of a system has beer: an acceptable way of characterizing the 
effectiveness of that system at specified operating conditions. Furthermore, several acceptable approaches have been developed for estimating MMP under a variety of conditions. In this screening method being developed, the method of Orr \& Silva ${ }^{26}$ was used to estimate the MMP of carbon dioxide containing entrainers as applied to a selected crude oil with known proportions of hydrocarbon components.

To use Orr \& Silva's approach, another assumption made was that the coefficients (equations 11 and 12) were assumed to remain constant for the carbon dioxide/entrainer mixtures being evaluated. However, this assumption may be in error, since the predicted benefit of the entrainer is a function of changing vapor fluid density, and Orr \& Silva ${ }^{26}$ have indicated that large changes in density of impure carbon dioxide can lead to erroneous results. Orr \& Silva cited the work of others doing similar studies for methane and other miscible gases showing that the characteristic densities of these fluids at MMP are substantially different from carbon dioxide, an $x$ the relationships represented in equations 11 and 12 may not be applicable to carbon dioxide entrainers.

In summary, solubilities were estimated at predetermined temperatures and pressures. If the solubilities exceeded those used in calculating MMP by the method of Orr \& Silva, ${ }^{26}$ the estimated solubility values were ignored. If the estimated solubilities were less than the predetermined concentrations in estimating MMP, then the limiting solubilities were used for concentration values. The method of Orr \& Silva (as explained below) was used to estimate the carbon dioxide/entrainer density at MMP and equations-of-state were used to calculate pressures. A lowering of MMP was considered an indication that the phase behavior of carbon dioxide was favorably altered by an entrainer to increase the extractability of the crude oil by carbon dioxide.

Solubility and phase behavior have been studied for a variety of compounds in supercritical carbon dioxide, nitrogen, and other gases. Various equations of state have been developed to relate phase behavior to composition, temperature, and pressure. However, as discussed elsewhere, 27 most equations of state do not adequately predict behavior of mixtures near the critical region of the system, and it is near or above this temperature and pressure region that the greatest enhancement of solublitiles is seen. Therefore, alternative approaches to that being proposed here do not appear promising at this time. The method of Orr \& Silva ${ }^{26}$ for estimating MMP is oriefly discussed below and is represented by the following equations:

$$
\rho_{\text {MMP }}=-0.524 F+1.189
$$

where $F<1.467$, and

$$
\rho_{M M P}=0.42
$$

where $F>1.467$. 


$$
\begin{aligned}
& F=\sum_{2}^{37} K_{i} w_{i} C_{2+1} \\
& w_{i C_{2+}}=\frac{w_{i}}{\sum_{i=2}^{37} w_{i}} \\
& \log K_{i}=a c_{i}+b,
\end{aligned}
$$

The variable $P_{M M P}=$ estimated carbon dioxide density at $M M P, F=$ weighted-composition factor, $K_{j}=$ normalized partition coefficient for carbon number $\mathrm{I}_{1} \mathrm{w}_{\mathrm{C}_{2}+}=$ normalized weight fraction of carbon number $\mathrm{I}$ in the $C_{2}+$ fraction, $w_{j}=$ the weight fraction of carbon number $i$ in the oil, $C_{j}=$ carbon number, $a=-0.04175$, and $b=0.7611$.

The relationships used by Orr \& Silva are based on the idea that carbon dio::ide has a characteristic density at MMP for a given oil. If the carbon dioxide density at MMP has not been experimentally determined, it can be estimated if a compositional analysis of the crude oil is available. Once the carbon dioxide ciensity is determined for a given temperature, the MMP may be estimated using suitable equations-of-state (EOS).

For this study, an accurate EOS was used to calculate the estimated MMP for carbon dioxide, 28 and the Redlich-Kwong EOS was used for carbon dioxide containing the entrainer. ${ }^{29}$ The coefficients to the Redlich-Kwong EOS were determined based to a first approximation on the mole factions of the respective fluids and their individually calculated coefficients. This approach is less reliable at iower pressures, and this fact should be kept in mind when evaluating the results.

Therefore, in addition to the limitations of the assumptions used in estimating MMP, this overall approach will inaccurately predict entrainer effects when the system pressures are low to moderate, when high-molecular-weight entrainers are being evaluated, when critical parameters are unknown, when no density data at MMP are known for the crude oil with carbon dioxide and entrainer, and when solution behavior deviates significantly from ideal fluids. Because many of these limitations apply to this investigation, inaccurate results were expected.

For purposes of pre-screening, the estimated MMP values for a variety of compounds at various concentrations were compared to determine if certain groups of compounds appear more beneficial than other groups. Because more emphasis with this screening approach is on identifying groups or types of compounds that appear promising than identifying individual compounds of greatest interest, the anticipated errors in this screening approach may be tolerable. Additional experimental evaluations would be needed before individual compounds could be seriously regarded as entrainer candidates.

Eighty-seven compounds were screened based on their critical properties (critical temperature, critical pressure, critical volume, vapor pressure, and density). The MMP was estimated for an arbitrarily 
selected crude oil (Wilmington (CA) fleld, Ford Zone). Because of the lack of information, some of the critical parameters for estimating solubilities and MMP of the entrainers were estimated for a few of these compounds using Somayajulu's procedures. ${ }^{30}$ Somayajulu used a series of molecular indices for estimating each of the critical parameters. Indices were developed for 180 or more molecular groupings that can be conveniently calculated using PC level machines. The errors for estimated values were determined by evaluating some 600 compounds, and in most cases the estimated critical parameters were within $5 \%$ of experimentally measured values. Of the 87 compounds evaluated, the critical volume was estimated for 28 compounds, the critical pressure was estimated for 8 cumpounds, and the critical temperature was estimated for 2 compounds.

Values of MMP were estimated for three concentrations of entrainer: 5.0 mole percent, 8.0 weight percent, and the maximum solubility in carbon dioxide for the given conditions. The MMP corresponding to the lowest amount of entrainer from these three choices was selected for screening. The reason for this selection was that if solubility is the limiting factor, the MMP reduction at the solubility limit would be selected. If solubility is not the limitation, then some reasonable amount would be selected based on economics, which in this case was arbitrarily selected as 8 weight percent or 5 mole percent, depending on the molecular weight of the compound. For higher molecular weight compounds, 8 weight percent would be selected.

The MMP factors corresponding to the selected quantities of the 87 compounds being screened are given in table 1. Those values near 1.0 indicate that very little benefit in MMP reduction by the chemical additive is expected. Those values near 0.0 indicate a large reduction in MMP is expected with the addition of the selected compound to carbon dioxide.

Two different temperature and pressure conditions were used to evaluate the estimated solubility ano' MMP parametors for the 87 compounds. For the first case, the temperature and pressure were $50^{\circ} \mathrm{C}$ and 1,396 psi, respectively. The temperature was close to the temperature at which the density at MMP was measured. 26 The assigned pressure was only used to estimate solubilities and was about average for the MMP range being considered. Because solubilities will vary as a function of pressure (or presumably MMP for an EOR application), the solubilities will not be very accurate. Also, because the pressure and temperature for this case were somewhat moderate, the application of the Redlich-Kwong EOS was considered inaccurate. This assessment was confirmed by using the Redlich-Kwong EOS to calculate MMP for pure carbon dioxide and sompared with a more accurate equation-of-state. ${ }^{28}$ Differences between the two values exceeded $25 \%$. Consequeritly, a higher temperature and pressure were also tested $\left(100^{\circ} \mathrm{C}\right.$ and $\left.2,790 \mathrm{psi}\right)$ and are shown as the second case in table 1. 
TABLE 1. - Comparison of MMP facters for entrainer czildidates with Wilmington (CA) crude oil.

\begin{tabular}{|c|c|c|}
\hline Enirainer candidate & $\begin{array}{l}\text { MMP factor, unitless }{ }^{1} \\
50^{\circ} \mathrm{C}, 95 \text { atm. }\end{array}$ & $\begin{array}{l}\text { MMP factor, unitless }{ }^{1} \\
100^{\circ} \mathrm{C}, 190 \mathrm{~atm} .\end{array}$ \\
\hline 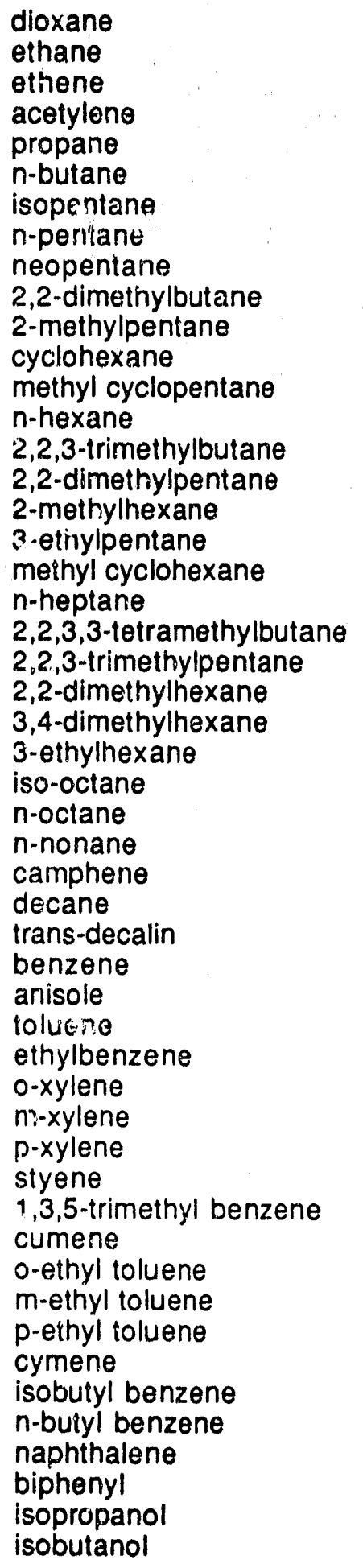 & 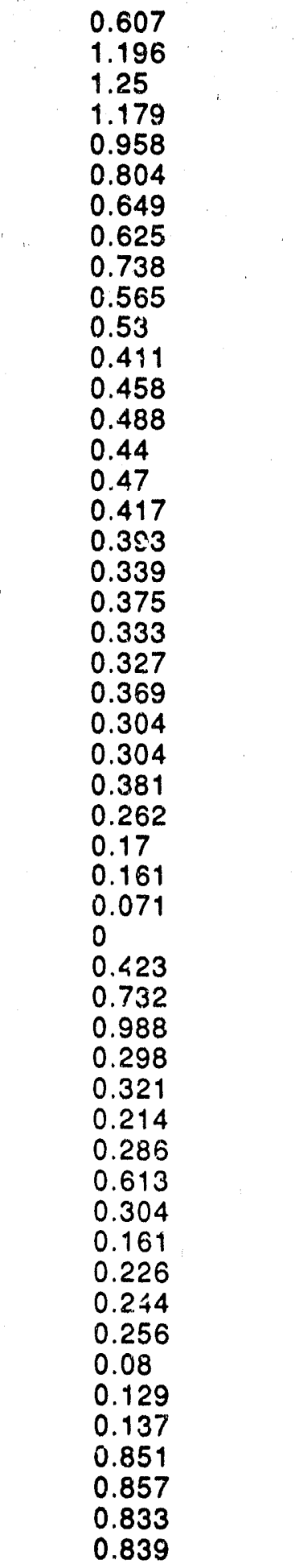 & $\begin{array}{l}0.707 \\
1.151 \\
1.186 \\
1.152 \\
1.014 \\
0.926 \\
0.851 \\
0.836 \\
0.889 \\
0.798 \\
0.786 \\
0.717 \\
0.742 \\
0.767 \\
0.736 \\
0.776 \\
0.726 \\
0.714 \\
0.697 \\
0.707 \\
0.679 \\
0.679 \\
0.701 \\
0.667 \\
0.67 \\
0.707 \\
0.654 \\
0.607 \\
0.585 \\
0.557 \\
0.501 \\
0.72 \\
0.613 \\
0.942 \\
0.626 \\
0.601 \\
0.617 \\
0.613 \\
0.582 \\
0.573 \\
0.588 \\
0.545 \\
0.576 \\
0.576 \\
0.545 \\
0.57 \\
0.551 \\
0.56 \\
0.485 \\
0.826 \\
0.736\end{array}$ \\
\hline
\end{tabular}


TABLE 1. - Comparison of MMP factors for entrainer candidates with Wilmington (CA) crude oil - Continued

\begin{tabular}{lll}
\hline Entraint; candidate & MMP factor, unitless ${ }^{1}$ & MMP factor, unitless \\
& $50^{\circ} \mathrm{C}, 95 \mathrm{~atm}$. & $100^{\circ} \mathrm{C}, 190 \mathrm{~atm}$. \\
\hline
\end{tabular}

$\begin{array}{lll}\text { 2-methylpentan-2-ol } & 0.476 & 0.704 \\ \text { 4-methylpentan-d.-ol } & 0.56 & 0.676 \\ \text { benzyl alcoho! } & 0.982 & 0.876 \\ \text { hexan-2-ol } & 0.72 & 0.657 \\ \text { n-heptanol } & 0.845 & 0.551 \\ \text { 2-ethyl hexanol } & 0.833 & 0.557 \\ \text { n-octanol } & 0.81 & 0.51 \\ \text { octan-2-ol } & 0.762 & 0.573 \\ \text { n-decanol } & 0.952 & 0.482 \\ \text { o-cresol } & 0.952 & 0.839 \\ \text { m-cresol } & 0.976 & 0.901 \\ \text { p-cresol } & 0.976 & 0.908 \\ \text { 4-s-butylphene } & 0.821 & 0.479 \\ \text { hexanoic acid } & 0.988 & 0.926 \\ \text { heptanoic acid } & 0.988 & 0.926 \\ \text { octanoic acid } & 0.994 & 0.92 \\ \text { nonanoic acid } & 0.988 & 0.911 \\ \text { decanoic acid } & 0.994 & 0.923 \\ \text { nitromethane } & 0.857 & 0.761 \\ \text { acrylonitrile } & 0.839 & 0.811 \\ \text { proprionitrile } & 0.667 & 0.726 \\ \text { nitrobenzene } & 0.976 & 0.92 \\ \text { n-caprylonitrile } & 0.893 & 0.679 \\ \text { carbon tetrachloride } & 0.613 & 0.776 \\ \text { chlorotorm } & 0.643 & 0.795 \\ \text { methyl chloride } & 0.869 & 0.939 \\ \text { 1,1-dichloroethane } & 0.911 & 0.792 \\ \text { ethvlene chloride } & 0.887 & 0.867 \\ \text { chloropropane } & 0.589 & 0.798 \\ \text { n-butyl chloride } & 0.482 & 0.745 \\ \text { chlorobenzene } & 0.56 & 0.651 \\ \text { 1,1-difluoioethane } & 0 & 0.51 \\ \text { fluorobenzene } & 0.476 & 0.732 \\ \text { for } & & \end{array}$

$1 \mathrm{MMP}$ factor $=\frac{\mathrm{MMPCO}_{2}+\text { entrainer }}{\mathrm{MMPCO}_{2}}$

For the first case, 39 of the 87 compounds screened had solubility values that were less than $8 \mathrm{wt}$ $\%$. Consequently, about one-half of the MMP values estimated for the first case were based on estimated solubilities of the respective compounds, and the validity of equation 8 affects the validity of the estimated overall result for many of the compounds. However, at $100^{\circ} \mathrm{C}$ and 2,790 psi, the solubilities of the entrainers in carbon dioxide were considerably increased, and only 16 of the 87 compounds evaluated were based on limiting solubilities. Therefore, in addition to the improved accuracy of the 
Redlich-Kwong EOS in the second case, the contribution of inaccurate solubility predictions to the overall results is reduced.

The Wilmington crude oil was selected because this oil was one of many crude oils used to calibrate the relationships in the work of Orr \& Silva, ${ }^{26}$ and was mid-range in MMP among all of the crude oils. The compositional analysis weight fractions used were those reported by Orr \& Silva and are $C_{5}-C_{12}(0.267)$, $C_{13}-C_{30}(0.384)$, and $C_{31+}(0.35) .26$

Several trends from the results are shown in table 1. An evaluation of the alkanes (table 1 and figure 2) shows that as the number of carbons in the alkyl chain are increased, the MMP is decreased (lower MMP factor). For the lower temperature case, values of MMP factor appruached 0 with decane and other longchain hydrocarbons. Such low values are unexpected, and when compared with the higher values for the higher temperature case, appear to be incorrect. As mentioned previously, the Redlich-Kwong EOS is inaccurate under these conditions and may he distorting the results.

Anothar trend is indicated by the aromatic compounds, as shown in figure 3 . With the exception of benzene and toluene, aromatic compounds appear to improve the MMP. The effect at the lower temperature appears more dominant for alkyl substituted mono-aromatic compounds. One reason why a similar effect is not seen in the higher temperature case is because the solubilities of naphthalene and biphenyl were higher for the second set of conditions.

Although most of the MMP factors were relatively high for alcohols, as shown in figure 4 , the increased temperature and pressure for the second case were sufficient to increase the solubilities for some of the compounds. That is why, for example, n-octanol and 2-ethyl hexanol had lower MMP factors for the second case as compared to the first case.

Because this approach of screening entrainer compounds has not been thoroughly evaluated by comparing with laboratory results, the accuracy of any of these predicted values is unknown. Although each of the respective methods has been evaluated individually, these methods have not been tested in the combined approach that is described in this section.

The reasons for the predicted decrease in MMP are twofold:

1. As the number carbons for the added entrainer are increased, the mixture density for the entrainer with the carbon dioxide also is increased. And as the mixture density is increased, the corresponding calculated MMP using the Redlich-Kwong EOS is decreased. While in principle this trend is reasonable, in practice the entrainer may partition between the carbon dioxide vapor phase and the crude oil liquid phase. The resulting predicted increase in vapor phase density would not be as dramatic and the corresponding decrease in MMP would not be as great as that shown in figures 2-4. 


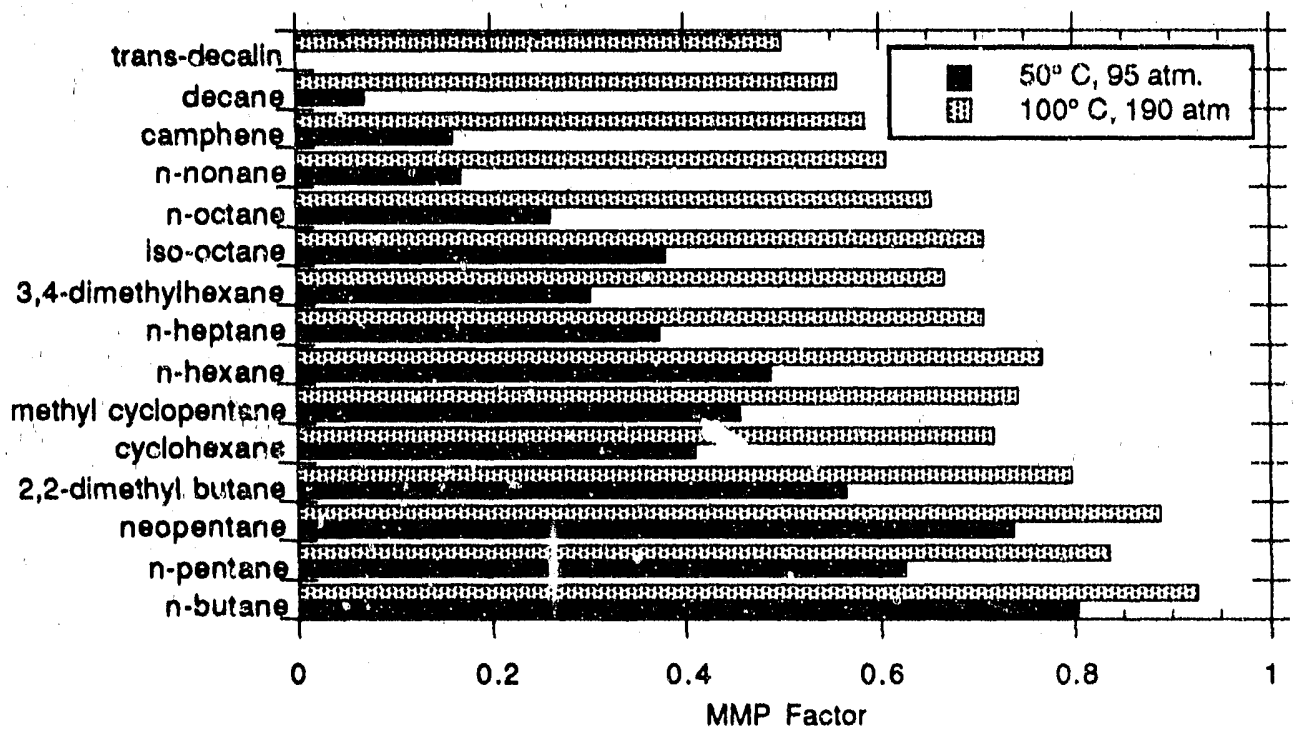

FIGURE 2. - Estimation of MMP faclor for a variety of hydrocarbons.

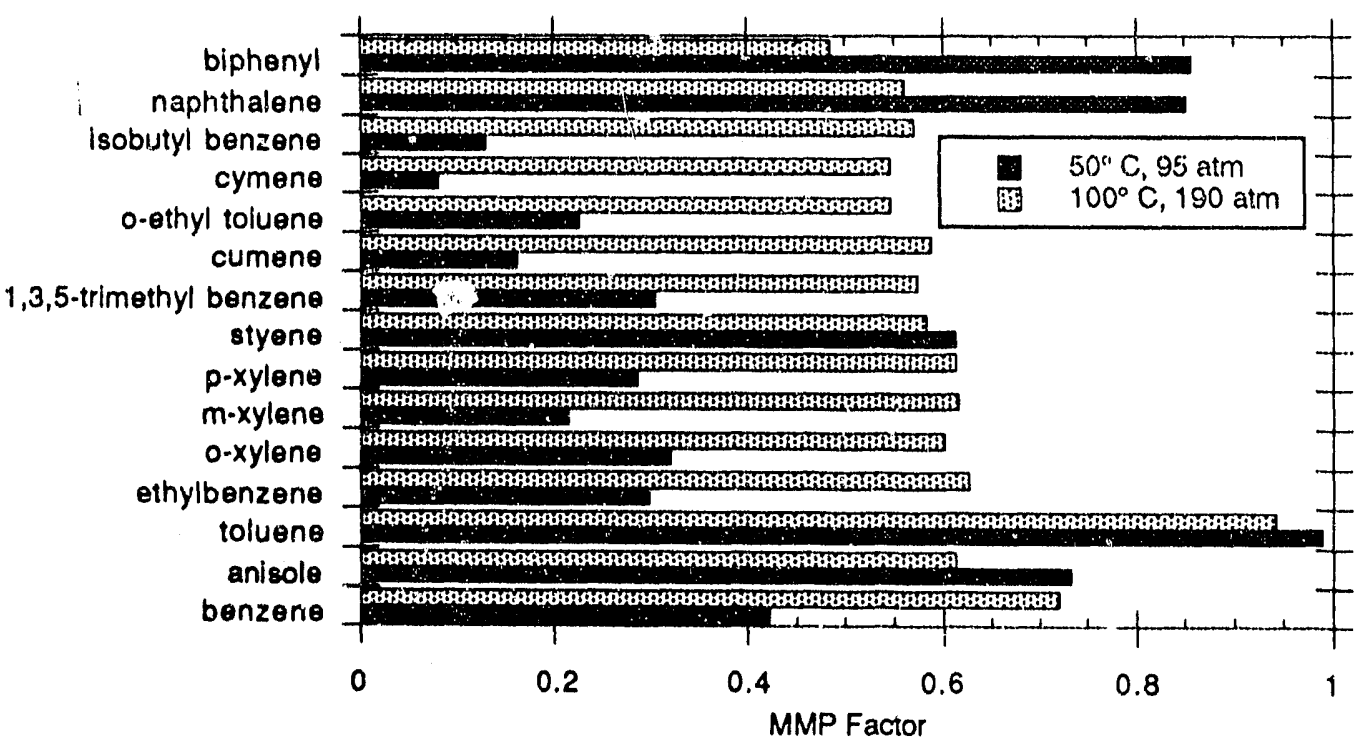

FIGURE 3. - Estimation of MMP factor for a variety of aromatic compounds. 


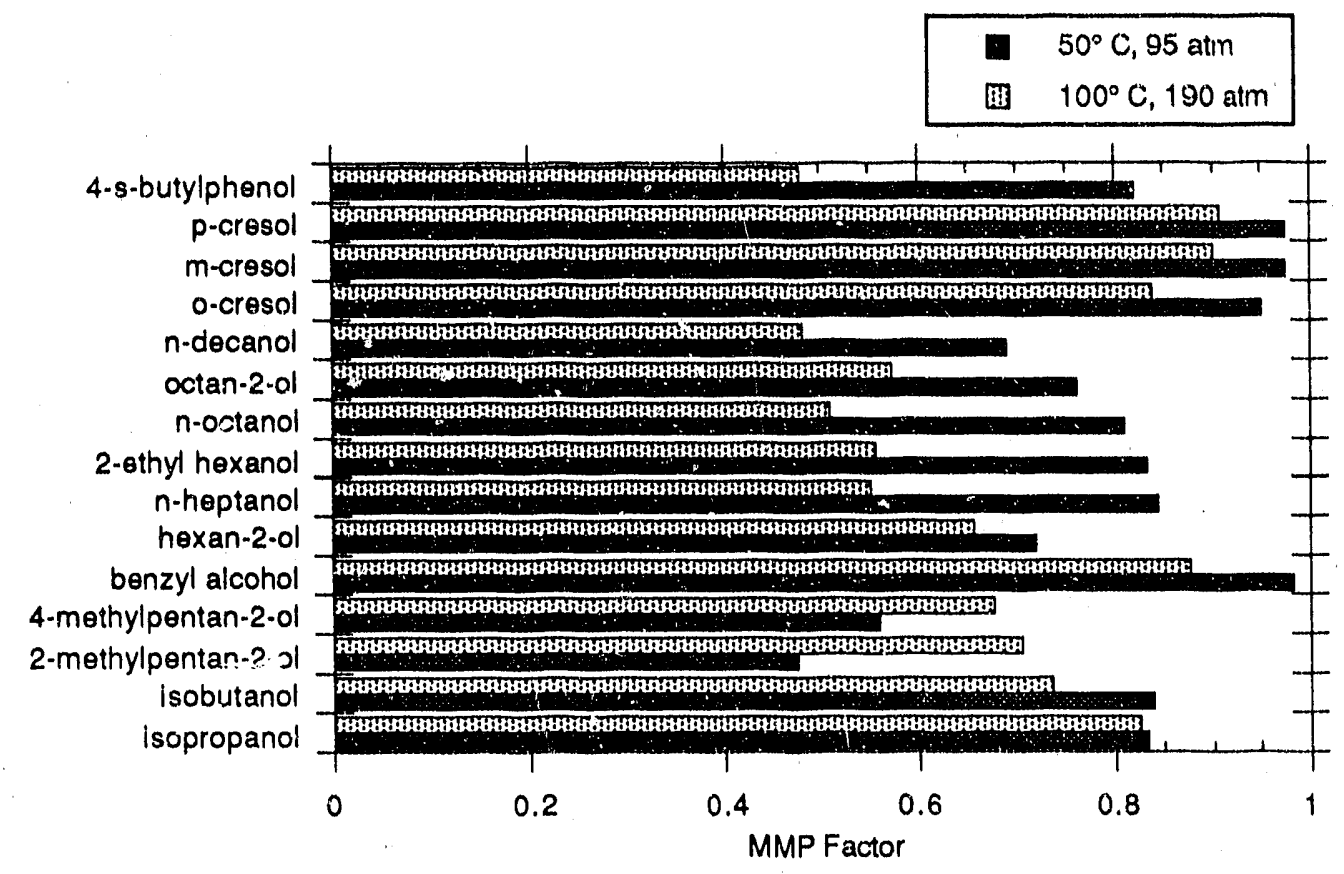

FIGURE 4. - Estimation of MMP factor for a variety of alcohols.

2. The hydrocarbons listed in table 1 are lighter than the average hydrocarbon component of the crude oil used in this report. Obviously, other crude oils may show different results for these same compounds. Christiansen ${ }^{31}$ discusses a procedure of enriching a vapor phase to render a bulk phase (otherwise immiscible) miscible with the vapor phase. The basic process described by Christiansen is similar to that evaluated in this report. An entrainer is used to enrich the carbon dioxide to render the mixture miscible with a bulk phase (Wilmington crude oil) at a pressure that would otherwise be immiscible-the MMP is lowered for the crude oil.

For the solubility estimation, the accuracy is limited by the assumptions made in the derivations, by the estimation of critical parameters, by fixing pressure to one value even though system pressures may vary, and by the estimation of the vapor pressure of the respective compounds for the conditions listed in table 1. For the estimation of carbon dioxide density with entrainer at MMP according to the method of Orr \& Silva, ${ }^{26}$ the accuracy is limited by the assumptions made in the derivation, by the simplifications made in the crude oil compositional analysis, and by the basic premise that the fluid density is constant at MMP with varying temperatures and vapor phase composition. For the determination of MMP from the carbon dioxide density, the accuracy is limited by the inability to predict more ideal gas behavior as the conditions approach the critical point. This difficulty is particularly significant for gas mixtures as was being evaluated in this section of the report. 
In conclusion, predictions based on certain theoretical principles are convenient for comparing many compounds to estimate their potential as entrainers in carbon dioxide and can be done very quickly. However, because of inaccuracies in critical data, of inaccuracies in estimated vapor pressures at conditions, and of the basic assumptions made for developing this approach, the final results of this approach are inconclusive. Furthermore, sufficient laboratory results on the use of these compounds have not been obtained, and the relative importance of one group of compounds over another as indicated by this predictive method remains unproven. Additional work is necessary before a final assessment of this screening method can be made.

\section{Viscosity And Density Measurements}

One desirable property the entrainer should impart on carbon dioxide fluids is added viscosity. The previously discussed screening procedure made the assumption that the viscosity enhancement by the entrainer was less important than the beneficial effects on carbon dioxide phase behavior. However, measuring in the laboratory the phase Lehavior changes as a function of entrainer and crude oil is very time consuming and would not be a very efficient laboratory screening tool. Furthermore, laboratory studies have not been done to determine conclusively whether the viscosity enhancement of the entrainer is a major or minor contributor to the overall performance of the system. Consequently, a laboratory screening procedure was developed at NIPER to measure the viscosity and density of carbon dioxide (or other gas) with entrainer added at any desired temperature and pressure. In addition, provisions were made to sample the fluid compositions from a sampling port directly to a gas chromatograph. From this information, entrainer concentrations could be correlated with measured fluid viscosities and densities. Although several compounds have been previously tested with this screening procedure, an additional compound, ethylene glycol, was tested this year to confirm incomplete results reported in a U.S. Patent. ${ }^{16}$

The apparatus used for measuring viscosities and densities of carbon dioxide mixtures was previously constructed at NIPER, and a schematic of it is shown in figure 5. Carbon dioxide was circulated through $50 \mathrm{~mL}$ of entrainer at selected pressures $(1,800,2,300$, and $3,000 \mathrm{psig})$ and temperature $\left(110^{\circ} \mathrm{F}\right)$ until equilibrium was reached. A determination of equilibrium was made based on the repeatability of viscosity measurements, and in most cases equilibrium was attained within 48 hours. The amount of ethylene glycol was in excess of the solubility in the gaseous carbon dioxide phase. Ethylene glycol was then allowed to reach saturation concentrations in the carbon dioxide before the carbon dioxide phase was evaluated. Although the apparatus can be used to measure viscosities and derisities of the liquid phase, such measurements were not made for this study. 


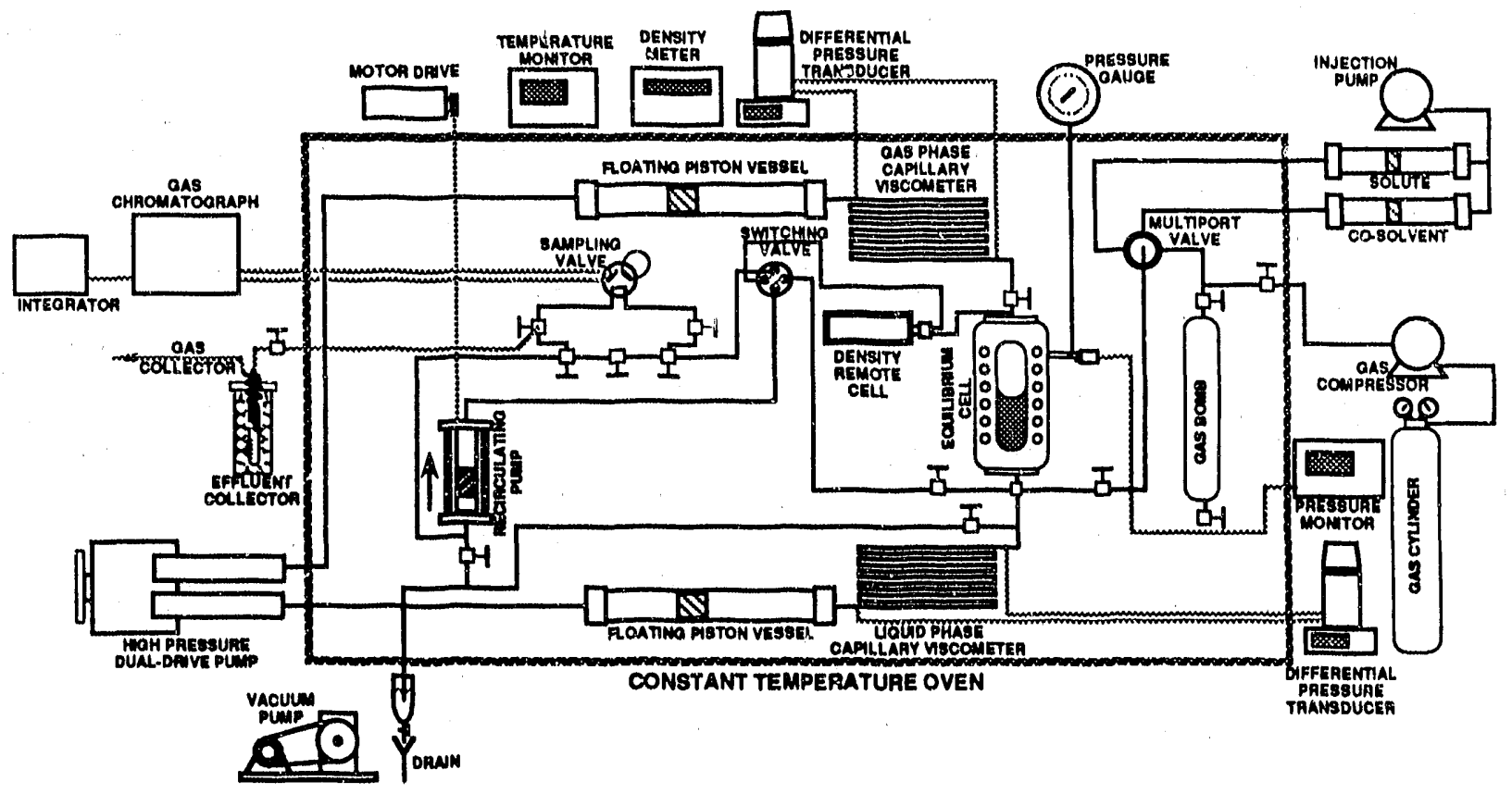

FIGURE 5. - Scherr.dtic diagram of entrainer capillary viscometer.

A comparison of the enhanced viscosities of supercritical carbon dioxide containing entrained ethylene glycol with carbon dioxide alone is shown in figures 6 and 7. The measured viscosities of the carbon dioxide/ethylene glycol mixture at various flow rates through the capillary tube are shown in figure 6 . The extrapolated value at a flow rate of $0 \mathrm{~cm}^{3} / \mathrm{hr}$ was then plotted with viscosities of carbon dioxide for the same temperatures and pressures (see figure 7). This procedure is common when viscosities are determined for non-Newtonian fluids, since the apparent viscosity is a function of the shear rate. As shown in figure 7, a slight enhancement in viscosity was noticed at the higher pressures. The GC analysis of the fluids indicated that in the non-liquid phase, the weight percent of ethylene glycol in the carbon dioxide was 0.64 at $1,800 \mathrm{psig}$ and 7.70 at $2,300 \mathrm{psig}$. These results indicated that as the system pressures are increased, the solubility of ethylene glycol in carbon dioxide increases, and the measured viscosities and densities of the entrainer mixture are correspondingly higher. These results contradict those reported by Stevens and Hawkins, ${ }^{16}$ where the viscosity of the carbon dioxide/ethylene gl/col mixture at $1235 \mathrm{psi}$ and $108^{\circ} \mathrm{F}$ was reported as $930 \mu \mathrm{P}$ and the weight percent ethylene glycol in the mixture was reported as 2.3. Our data indicate that othylene glycol does not appear to be soluble in carbon dioxide under these conditions and that no enhancement of viscosity is expected. 


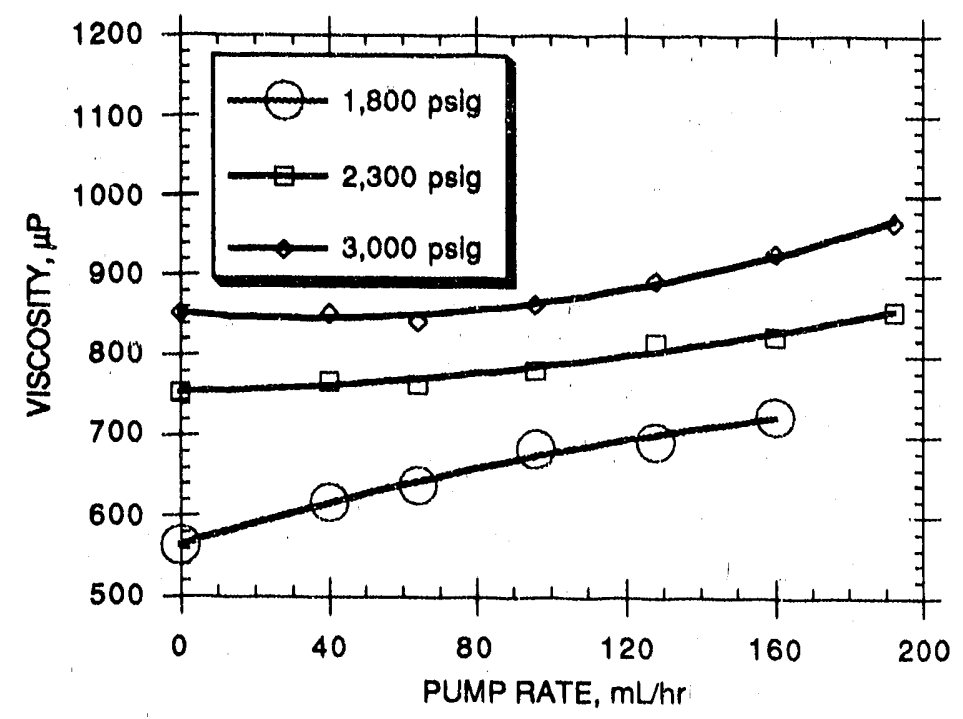

FIGURE 6. - Plot of viscosity as a function of shear rate for ethylene glycol in carbon dioxide $\left(110^{\circ} \mathrm{F}\right)$.

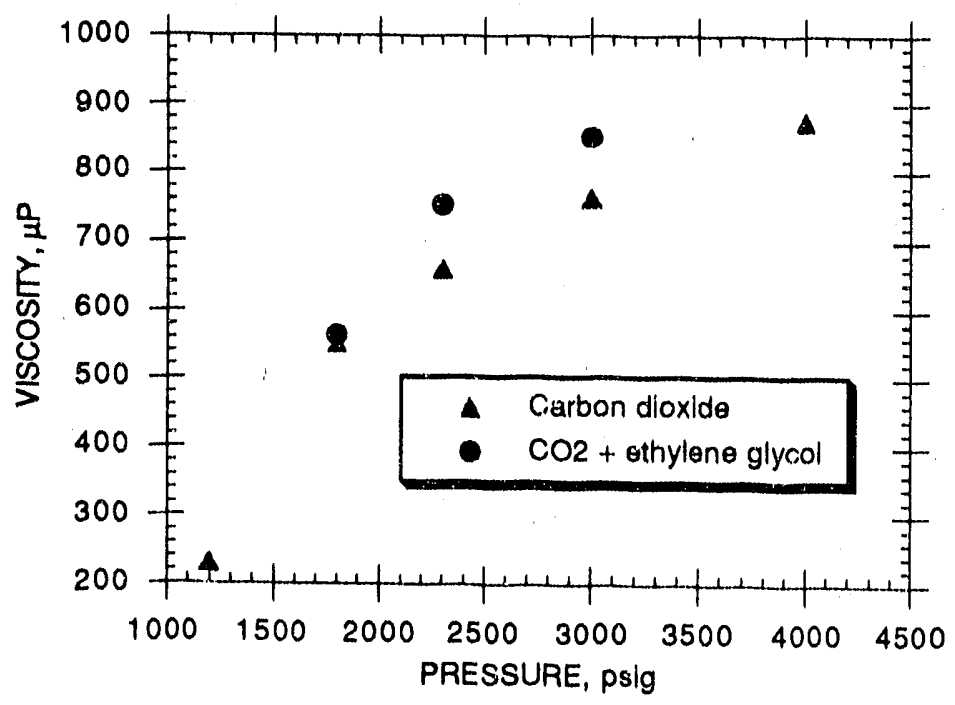

FIGURE 7. - Comparison of viscosity for carbon dioxide and carbon dioxide plus ethylene glycol. 
This screening method and results of n-decanol, iso-octane, 2-ethylhexanol, and an ethoxylated alcohol have been reporter 32 In addition to conducting these screening issts, corefloods were conducted to eviluate the relative performance of the compounds as carbon dioxide entrainers. The report ${ }^{19}$ implies that iso-octane and 2-ethylhexanol appeared to be good entrainer candidates under the conditions lested. The screening procedure of measuring viscositles and densities for these compounds indicates in this report that iso-octane and 2-ethylhexanol are better than $n$-decanol and the ethoxylated alcohol. Coreflood experiments in that work indicated that both compounds improved oil recovery, which supported the conclusions obtained from the screening experiments. No significant difference was determined between iso-octane and 2-ethylhexanol.

However, based on literature reports $n$-decanol is about 17 times less soluble than 2-ethylhexanol in carbon dioxide, with the solubility of n-decanol in carbon dioxide being about $1 \%$. Using the mathematical screening method described in the previous section, the MMP factor was found to be limited by the solubilities for both compounds. The predicted solubilities were reasonably close for $n$-decanol, but the method did not adequately predict the solubility of 2-ethyl hexano!. If the solubility in carbon dioxide was also low for the ethoxylated alcohol, then the relative performances of the tested compounds in the previous report ${ }^{33}$ could be explained as much by their relative solubilities as their contributions to viscosities. Because of the confounded effects of solubility and viscosity, it was not possible to use the available data to support the contention that the described laboratory screening method effectively predicts which compounds will be the best entrainers.

The advantage for using this procedure over the previous mathematical procedure is that until the mathematical method is proven to be sufficiently accurate, laboratory measured data will always be more reliable. One disadvantage to this method is that the direct contribution of viscosity enhancement by entrainers has not been proven to be the most important property of the successful entrainer. An additional disadvantage is that 24 to $48 \mathrm{hr}$ is required to achieve equilibrium at each pressure and temperature for this procedure, and five or more different flow rate measurements are needed at each set of conditions to obtain the extrapolated solution viscosity. This condition is true because apparent viscosities are a function of different shear rates, or for our case different flow rates. Consequently, several weeks may be needed to evaluate each compound. A quicker procedure would be preferred if one could be developed.

\section{Gas Chromatography}

Gas chromatography is a process where a carrier gas is continually flowed through a column containing an inert support material and an immobile liquid that is physically adsorbed onto the inert material. Compounds being screened are injucted into the carrier gas, helium, and the time required for the injected material to pass through the column is measured. The elution times vary depending upon the 
relative affinity of the injected material to the carrier gas and the immoblle liquid. The more favorable the partitioning to the statior ary liquid phase, the longer the elution time should be of the injected material.

In principle, gas chromatography could be used to model certain aspects to fluid flow through reservoir material, since the reservoir rock and residual fluids are analogous components to GC columns. In this situation, the use of gas chromatography was considered ac a screening tool for evaluating relatlve affinities of compounds to particular residual fluids such as hydrocarbons. Those whose partitioning favored the hydrocarbon liquids more than the carrier gas would have longer retention times and presumably would be more favorable entrainers for carbon dioxide floods. Furthermore, GC technology and equipment are well developed, and a compound may be evaluated in a relatively short period of time. The concept of using this process ma; be extended a little further to exchange the carrier gas from helium to a supercrilical fluid such as carbon dioxide. Although not as well developed, supercritical fluid chromatography is now considered an established procedure and may be an even better screening procedure than gas chromatography. However, because GC analyses are more convenient, readily available, and less expensive, a study' was initiated last year to determine if this technique could be used effectively to screen chemicals for use as entrainers. Some of the rosults obtained were reevaluated and compared with related experiments to determine if this procedure could be used effectively to screen entrainers.

The procedures outlined for gas chromatography were considered in this study for evaluating the relative affinities of various compounds to heavier hydrocarbons. Several stationary phase materials were packed in columns for gas chromatography. A variety of entrainer candidates was then injected to determine their elution times and, therefore, their relative affinities to the respective stationary phases. A detailed discussion of the experimental procedures and results has been published. ${ }^{33}$

The compounds evaluated using the GC technique include n-heptane, benzene, toluene, acetone, ethanol, methanol, ammonia, chloroform, iso-octane, petroleum ether, and 2-ethylhexanol. Their elution times were determined on columns packed with (1) UICW-982 (a methyl silicone liquid phase), (2) 32 wt \% UCW-982 + 68 wt \% n-pentacosane $\left(n-C_{25}\right),(3) 87$ wt \% UCW-982 + 64 wt \% ntriacontane $\left(n-C_{30}\right)$, and (4) 54 wt \% UCW-982 + $46 w t \% n$-tetracontane $\left(n-C_{40}\right)$. The purpose of the experiment was to determine if the relative affinity of these compounds to the liquid phase on the columns, as measured by the retention times, could be used to compare the relative benefits as an entrainer in carbon dioxide. Unlike supercritical fluid chromatography, the pressure conditions do not approximate carbon dioxide floods, and the carrier gas is not carbon dioxide. However, as, a screening tool, this procedure would be quick and would test the relative affinity of various compounds of hydrocarbon liquid phases to a moving gas phase.

Table 2 gives the Rf values (based on elution time of $n$-heptane) for the respective columns at various injection volumes of chemicals. Two properties were being sought: (1) a relative ranking of compounds that are comparable with the density, viscosity, and extraction results measured for some 
entrainers in carbon dioxide and (2) a response to hydrocarbon liquid stationary phases that compare similarly to the extraction propertles with carbon dloxide and entrainers of selective hydrocarbons.

TABLE 2. - Rf values from GC analysis of various compounds on selected hydrocarbon stationary phases

\begin{tabular}{|c|c|c|c|c|c|}
\hline Compound & $\begin{array}{c}\text { Injection } \\
\text { volume, } \\
\text { ricroliters }\end{array}$ & $\begin{array}{c}100 \% \\
\text { UCW-982, } \\
\text { Rf }^{1}\end{array}$ & $\begin{array}{l}68 \% \\
\mathrm{C}_{25} \text {, } \\
\mathrm{Rf}^{1}\end{array}$ & $\begin{array}{l}64 \% \\
\mathrm{C}_{30} \\
\mathrm{Rf}^{1}\end{array}$ & $\begin{array}{c}46 \% \\
\mathrm{C}_{40} \\
\mathrm{Rf}\end{array}$ \\
\hline $\begin{array}{l}\text { n-Heptane } \\
\text { n-Heptane } \\
\text { n-Heptane } \\
\text { Benzene } \\
\text { Benzene } \\
\text { Benzene } \\
\text { Toluene } \\
\text { Toluene } \\
\text { Toluene } \\
\text { Acetone } \\
\text { Acetone } \\
\text { Acetone } \\
\text { Ethanol } \\
\text { Ethanol } \\
\text { Ethanol } \\
\text { Methanol } \\
\text { Methanol } \\
\text { Methanol } \\
\text { Ammonia } \\
\text { Ammonia } \\
\text { Ammonia } \\
\text { Chloroform } \\
\text { Chloroform } \\
\text { Chloroform } \\
\text { Iso-octane } \\
\text { Iso-octane } \\
\text { Iso-octane } \\
\text { Petro. Ether } \\
\text { Petro. Ether } \\
\text { Petro. Ether } \\
\text { 2-ethyl hexanol } \\
\text { 2-ethyl hexanol } \\
\text { 2-ethyl hexanol }\end{array}$ & $\begin{array}{l}0.10 \\
0.30 \\
0.50 \\
0.10 \\
0.30 \\
0.50 \\
0.10 \\
0.30 \\
0.50 \\
0.10 \\
0.30 \\
0.50 \\
0.10 \\
0.30 \\
0.50 \\
0.10 \\
0.30 \\
0.50 \\
0.10 \\
0.30 \\
0.50 \\
0.10 \\
0.30 \\
0.50 \\
0.10 \\
0.30 \\
0.50 \\
0.10 \\
0.30 \\
0.50 \\
0.10 \\
0.30 \\
0.50\end{array}$ & $\begin{array}{l}1.00 \\
1.12 \\
1.18 \\
0.65 \\
0.72 \\
0.74 \\
1.63 \\
1.85 \\
1.99 \\
0.19 \\
0.21 \\
0.30 \\
0.19 \\
0.24 \\
0.28 \\
0.14 \\
0.16 \\
0.18 \\
0.31 \\
0.61 \\
0.96 \\
0.45 \\
0.46 \\
0.49 \\
0.90 \\
1.00 \\
1.07 \\
0.22 \\
0.22 \\
0.21 \\
9.26 \\
11.65 \\
13.69\end{array}$ & $\begin{array}{l}1.00 \\
1.11 \\
1.14 \\
0.70 \\
0.69 \\
0.69 \\
1.48 \\
1.76 \\
1.96 \\
0.34 \\
0.33 \\
0.36 \\
0.34 \\
0.43 \\
0.55 \\
0.33 \\
0.36 \\
0.37 \\
0.50 \\
0.61 \\
1.53 \\
0.53 \\
0.55 \\
0.58 \\
0.89 \\
0.97 \\
0.98 \\
0.34 \\
0.33 \\
0.33 \\
23.83 \\
28.88 \\
28.93\end{array}$ & $\begin{array}{l}1.00 \\
1.17 \\
1.19 \\
0.65 \\
0.76 \\
0.82 \\
1.32 \\
1.54 \\
1.72 \\
0.34 \\
0.40 \\
0.42 \\
0.39 \\
0.54 \\
0.56 \\
0.31 \\
0.42 \\
0.48 \\
0.99 \\
2.44 \\
3.84 \\
0.50 \\
0.50 \\
0.63 \\
0.81 \\
0.93 \\
0.99 \\
0.37 \\
0.35 \\
0.35 \\
6.94 \\
11.63 \\
14.42\end{array}$ & $\begin{array}{l}1.00 \\
1.15 \\
1.29 \\
0.74 \\
0.86 \\
0.81 \\
1.30 \\
1.70 \\
1.83 \\
0.35 \\
0.42 \\
0.45 \\
0.39 \\
0.51 \\
0.59 \\
0.37 \\
0.43 \\
0.54 \\
1.19 \\
2.00 \\
3.38 \\
0.60 \\
0.74 \\
0.67 \\
0.84 \\
1.04 \\
1.07 \\
0.40 \\
0.39 \\
0.42 \\
9.18 \\
15.92 \\
22.77\end{array}$ \\
\hline
\end{tabular}

${ }^{1}$ Although the confidence intervals were not determined for each value specifically, a pooled estimate of the variance was made. For all except 2-ethyl hexanol, the varlance is 0.0035 , and for 2-ethyl hexanol the variance is 0.905 . 
To check the rellabllity of the ranking of compounds using the GC method for screening, the GC results of 2-ethylhexanol and iso-octane were compared to results obtained from extracting $\mathrm{n}$-hexadecane with carbon dloxide alone and carbon dioxide with 2-ethylhexanol or iso-octane. ${ }^{33}$ The results of the extraction experiment were determined by measuring the densities of carbon dioxide, carbon dioxide with extracted $n$-hexadecane, carbon dioxide and iso-octane with extracted $n$-hexadecane, and carbon dioxide and 2-ethylhexanol with extracted $n$-hexadecane over a range of pressures $(800$ to $3,000 \mathrm{psi})$. The mole fraction of hexadecane in the extraction fluld was also measured. A summary of results from the extraction experiments is given in table 3.33

As shown in table 3, 2.ethyihexanol increased the viscosity and density of the carbon dloxide more than the iso-octane, but the amount of additional hexadecane recovered was greater using isooctane. However, the results in table 2 and figure 8 of the GC experiment showed that partitioning of 2-ethylhexanol into the statlonary liquild phase of the GC column was substantially more favored than any of the other compounds tested--including iso-octane. The retention index was much larger iur 2-ethylhexanol than for any of the other compounds. Therefore, this initial study to evaluate the GC method for screening entrainer candidates indicates that the processes being evaluated by GC are too different from gas flooding-entrainer EOR processes to assess adequately the potential of entrainer candidates.

Also, a comparison of the MMP factors in table 1 indicates that 2-ethylhexanol would not be expected to benefit carbon dioxide extraction as much as iso-octane according to the assumptlons presented for the mathematical screening technique discussed previously. The reason for this is that 2-ethylhexanol was not predicted to be particularly soluble in carbon dioxide and the effectiveriess as an entrainer would be limited by its solubility. Although perhaps circumstantial, this assessment does agree with the results indicated in table 3 for the relative amounts of hexadecane extracted for each entrainer, and of course, further indicates that using the GC technique to screen compounds for gas flooding entrainers may not be effective.

Instead of comparing different compounds on a given GC column as a way of identifying the better candidates, an alternative approach was considered. The relative retention times of differemi compounds were evaluated as a function of their relative response to the different hydrocarbon stationary liquid phases. As an example, those compounds tested that had retention times much longer for the $\mathrm{C}_{40}$ columns than the $\mathrm{C}_{25}$ columns with reference to other compounds tested might be selected for applications requiring heavier crude olls. However, as shown in table 2, relative to n-heptane none of the compounds except ammonia and perhaps 2-ethylhexanol showed any significant difference in retention times within experimental error to any of the stationary phases. Furthermore, the differences observed for 2-ethylhexanol appear to be inconsistent with respect to the three liquid stationary phases, and therefore are also suspect. The experimental error was estimated based on twice the estimated standard deviation (this would include $95 \%$ of data distributed normally about a mean). 
TABLE 3. - Comparison of entrainer-anhanced gas phase properties at $60^{\circ} \mathrm{C}$ and $2,200 \mathrm{psig}$

\begin{tabular}{|c|c|c|c|}
\hline $\mathrm{cP}(\%$ incr & $\begin{array}{l}\text { cosity } \\
\text { ase from } \mathrm{CO}_{2} \text { ) }\end{array}$ & $\begin{array}{c}\text { Density } \\
\mathrm{g} / \mathrm{mL}\left(\% \text { increase from } \mathrm{CO}_{2}\right)\end{array}$ & $\begin{array}{l}\text { Mole fraction extracted } n-C_{16} \\
\left(\% \text { Increase from } \mathrm{CO}_{2}+n-C_{16}\right)\end{array}$ \\
\hline Carbon dioxide & 0.0421 & 0.55 & NA \\
\hline $\begin{array}{l}\text { Carbon dioxide } \\
\text { thexadecane }\end{array}$ & $0.046 \%(9.8 \%)$ & $0.5824(5.9 \%)$ & 0.0216 \\
\hline $\begin{array}{l}\text { Carbon dioxide } \\
(188.4 \%) \\
\text { +hexadecane } \\
\text { +iso-octane }\end{array}$ & $0.0524(24.4 \%)$ & $0.6256(\% 13.8 \%)$ & 0.0623 \\
\hline $\begin{array}{l}\text { Carbon dioxide } \\
+n-C_{16}+2 \text {-ethyl hexanol } \\
(102.3 \%) \text { +hexadecane } \\
+2 \text {-ethyl hexanol }\end{array}$ & $0.0619(47 \%)$ & $0.6542(19 \%)$ & 0.0437 \\
\hline
\end{tabular}

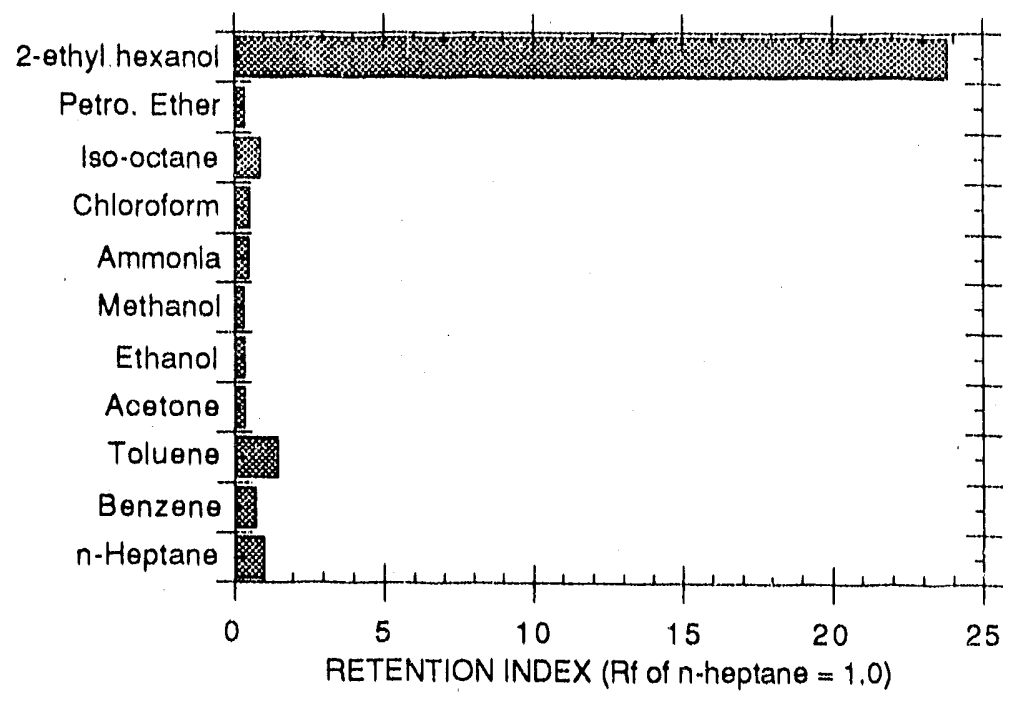

FIGURE 8. - Retention indices of selected compounds on $\mathrm{C}_{25} \mathrm{GC}$ column. 
Also, the relative amounts of these components $\left(\mathrm{C}_{25}, \mathrm{C}_{30}\right.$, and $\left.\mathrm{C}_{40}\right)$ extracted from a crude oil with carbon dioxide and iso-octane were different by at least one order of magnitude, and the results clearly showed that the $C_{25}$ components were extracted preferentially to the $C_{30}$ or $C_{40}$ components. ${ }^{26}$ Indeed, the GC analysis indicated that the measured retention times were significantly different, but were substantially longer for the $\mathrm{C}_{40}$ column than the $\mathrm{C}_{25}$ column. All of the compounds tested with the GC columns had a greater preference for the $C_{40}$ liquids than the $C_{25}$ liquids, and all but ammonia appeared to have a similar preference for the respective stationary phases. Based on these results, there appears to be no valid basis fur using retention times or relative retention times to compare candidates for entrainer applications.

In summary, using the GC method for screening candidates for entrainer applications is convenient and quick. However, the initial results of the column substrates tested do not show any meaningful relationship between retention times on GC columns and mobility control or extractability of crude oil with carbon dioxide.

A further investigation into the use of supercritical fluid chromatography (SFC) as a screening method for entrainers is recommended. However, initial investigations into this technique show that initial setups are expensive, method development is time consuming, and ultimately it is uncertain whether such a procedure would be any more effective than the GC method. As with gas chromatography, supercritical fluid chromatography evaluates the relative affinities of injected compounds to the column substrate. This process has little relationship to entrainer EOR applications where the supercritical fluids extract the "substrate" liquid (crude oil) from the rock pores.

\section{Final Assessment}

Three approaches were considered as screening tools for evaluating compounds as entrainers in carbon dioxide: use of mathematical predictions based on theoretical principles, use of a capillary viscometer apparatus to measure viscosities and densities, and use of a gas chromatograph to evaluate relative retention times on hydrocarbon-based columns.

The use of mathematical predictions to identify compounds that may be ideally suited as a carbon dioxide entrainer has the advantage of being convenient and quick. The program is not very large, which enables this procedure to be implemented on microprocessor computers in a variety of ways. The use of spreadsheets is even possible with this approach. However, the disadvantage $0 i$ this approach is that the equations require many assumptions that introduce inaccuracies into the final results. Furthermore, accurate data on the critical parameters (critical temperature, pressure, molar volume, etc.) and vapor pressures at the conditions being evaluated are needed but are not always readily available. This information may be known for some compounds, but not for all compounds. In situations where this information is not available, additional inaccuracies are introduced by estimating the values from available procedures. The overall result is that screening potentlal entrainers using mathematical prediction 
methods may be an effective tool for evaluating a class of compounds, but this method is not reliable for evaluating particular compounds and the described approach remairs unproven.

The use of the capillary viscometer to evaluate the viscosity and density enhancements of entrainers in carbon dioxide has the advantage of providing laboratory measured values. Entrainers do add viscosity to carbon dioxide fluids, and this approach can determine which compounds are the most effective viscosifier. However, one disadvantage is that sufficient laboratory experiments have not been conducted to establish this property of directly viscosifying the carbon dioxide as the most important property for entrainers. The ability to enhance the extraction of hydrocarbons in the reservoir which themselves enhance the overall viscosity of the fluids may be more important to the overall technical success of the process. A second disadvantage is that conducting these experiments are time consuming--a factor that is usually avoided for screening methods. At least 24 to $48 \mathrm{hr}$ is required to allow the system to reach equilibrium for each temperature and pressure being evaluated. Once equilibrium is reached, five or more different pump rates are run with corresponding measurements to derive one viscosity measurement. In addition, at least three or four different pressures are tested to get a curve function over a reasonable pressure range before the behavior of the compound being tesied can be fairly evaluated. Based on this schedule, a minimum of 2 to 3 weeks is required to test just one compound. Therefore, although this procedure is more accurate then the mathematical prediction approach, it is time consuming and depending solely on this method for screening may preclude the final testing of some effective entrainers.

The use of the gas chromatograph as a screening tool has the advantage of being quick--an ideal properiy of a screening procedure. However, no evidence was found that the results have any relationship to gas flooding/entrainer recovery mechanisms; therefore, the use of this procedure for screening candidates for carbon dioxide/entrainer applications is not recommended. Although supercritical fluid chromatography has the appearances of being more similarly related than gas chromatography to gas flooding, the same differences in mechanisms being evaluated exist. Measurement of elution times in gas chromatography or supercritical flu:d chromatography evaluates the relative affinity of the compound to the column substrate over the flowing gas. The tests conducted with gas chromatography seemed to indicate that those compounds having a greater affinity for the liquid substrate in the column, such as a hydrocarbon, do not necessarily have any bearing on the ability of that compound to extract the hydrocarbon into the gas phase or alter the gas phase in a beneficial way to enhance the effectiveness of the recovery process. Apples and oranges are being compared with these screening procedures.

Therefore, unless another screening procedure is developed, it is recommended that the capillary viscometer should be used to determine which compounds are suitably soluble and provide adequate viscosity enhancements to the gas being considered for EOR. The final assessment can only be made under coreflood conditions containing the crude oil, core, brine, and injected gas. 


\section{CONCLUSIONS}

A variety of studies was conducted with entrainer compounds to advance this technology. Entrainers are compounds added to gases - typical supercritical gasses such as carbon dioxide - to enhance certain beneficial properties of the gas to extract desirable components. For EOR, entrainers are being sought to enhance the extractability of crude oil by a supercritical gas such as carbon dioxide, and if possible, to improve the mobility control of the gas by increasing its viscosity. Predictive methods and other screening methods were evaluated to find more efficient ways of identifying good entrainers for a given situation. Adsorption of entrainers was also evaluated for Berea sandstone cores.

Methods of predicting solubilities that can be applied to entrainer systems were evaluated. Two approaches $w$ re considered: estimation based on general phase equilibrium theory and estimation based on derivations from fluctuation theory (Kirkwood-Buff solution theory). The latter approach appears to be the best, although the accuracy is limited to dilute solutions.

Screening methods were evaluated for entrainer systems. The three approaches considered were mathematical predictive methods, measurement of viscosities with a capillary viscometer, and measurement of relative affinities with gas chromatography. Gas chromatography is ineffective as a screening tool. Mathematical predictive methods remain unproven and are not effective for accurately screening individual compour.ds. Use of a capillary viscometer is currently the best method at NIPER to screen compounds for entrainer applications. Disadvantages for this approach include relatively long evaluation times and the uncertainty that the measured properties may not be the most significant with respect to oil recovery.

\section{ACKNOWLEDGMENTS}

The authors acknowledge the contributions made by Ray Jones and Frank Chung of NIPER. Many of the laboratory procedures and equipment designs were developed by Ray Jones. All of the work presented in the development of equations for estimating solubilities and many subsequent suggestions for improving this report were provided by Frank Chung. The authors also acknowledge the financial support of this work provided by the U.S. Department of Energy under Cooperative Agreement DE-FC22$83 F$ F $^{-60149 .}$

\section{REFERENCES}

1. Gardner, J. W., F. M. Orr, Jr., and P. D. Patel. The Effect of Phase Behavior on $\mathrm{CO}_{2} \mathrm{FloOu}$ Displacement Etficiency. J. Pet. Tech., v. 33, No. 11, November 1981, pp. 2067-2081.

2. Orr, F. M., Jr., A. D. Yu, and C. L. Lein. Phase Behavior of $\mathrm{CO}_{2}$ and Crude Oil in Low Temperature Reservoirs. Soc. Pet. Eng. J., v. 21, No. 4, August 1981, pp. 480-492.

3. Holm, L. W. and V. A. Josendal. Effect of Oil Composition on Miscible-Type Displacement by Carbon Dioxide. Soc. Pet. Eng. J., v. 22, No. 1, February 1982, pp. 87-98. 
4. U.S. Dept. of Energy. Oll Research Program Implementation Plan. DOE Report DOE/FE-0188P, April 1990, 144 pp.

5. U.S. Dept. of Energy. Oil Research Program Implementation Plan. DOE Report DOE/FE0188P, April 1990, p. D-2.

6. Heller, J. P., D. K. Dandge, R. J. Card, and L. G. Donaruma. Direct Thickeners for Mobility Control of $\mathrm{CO}_{2}$ Floods. Pres. at the Soc. Pet. Eng. Int'l Symp. on Oiffield and Geothermal Chemistry, Denver, June 1-3, 1983. SPE Paper 11789.

7. Dandge, D. K. and J. P. Heller. Polymers for Mobility Control in $\mathrm{CO}_{2}$ Floods. Pres. at the Soc. Pet. Eng. Int'l Symp. on Oiffield Chernistry, San Antonio, Feb. 4-6, 1987. SPE paper 16271.

8. Terry, R. E., A. Zaid, C. Angelos, and D. L. Whitman. Polymerization in Supercritical $\mathrm{CO}_{2}$ to Improve $\mathrm{CO}_{2} / \mathrm{Oil}$ Mobility Ratios. Pres. at the Soc. Pet. Eng. Int'l Symp. on Oilfield Chemistry, San Antonio, Feb. 4-6, 1987. SPE paper 16271.

9. Peter, S., G. Brunner, and R. Riha. DECHEMA: monograph, v. 73, 1974.

10. Brunner, G., and S. Peter. Chem. Ing. Tech., v. 53, 1981, p. 259.

11. Panzer, F., S. R. M. Ellis, and T. R. Bolt. Inst. Chem. Eng. Symp. Series No. 54, 1978, p. 165

12. Brunner, a. Selectivity of Supercritical Compounds and Entrainers with Respect to Model Substance. Fluid Phase Equilibria, v. 10, 1983, pp. 289.

13. Joshi, D. K., and J. M. Prausnitz. Supercritical Fluid Extraction with Mixed Solvents. AIChE J., v. 30, No. 3, 1984, pp. 522-525.

14. Walsh, J. M., G. D. Ikonomou and M. D. Donohue. Supercritical Phase Behavior: The Entrainer Effect. Fluid Phase Equilibria, v. 33, 1987, pp. 295-314.

15. Schmitt, W. J. and R. C. Reid. The Use of Entrainers in Modifying the Solubility of Phenanthrene and Benzoic Acid in Supercritical Carbon Dioxide and Ethane. Fluid Phase Equilibria, $v$. i2, 1986, pp. 77-99.

16. Stevens, James F., Jr., Jeffrey T. Hawkins. Recovering Hydrocarbons with a Mixture of Carbon Dioxide and Alcohol. IJ.S. Patent 4,800,957, January 1989.

17. Hartman, Kathy U. and Winston F. Shu. Miscible Oil Recovery Process. U.S. Patent $4,678,036$, July 1987 .

18. Kokolis, George P. Carbon Dioxide and Hydrocarbon Solvent Flooding in a Steeply Dipping Reservoir. U.S. Pateni 4,570,712, February 1986.

19. Cullick, Alvin S. Enhanced Oil Recovery Using Carbon Dioxide. U.S. Patent 4,609,043, September 1986.

20. Djabbarah, Nizar F. Oil Recovery Method Employing Carbon Dioxide Flooding with Improved Sweep Efficiency. U.S. Patent 4,605,066, August 1986. 1989.

21. Irani, Cyrus A. Solubilizing Surfactants in Miscible Drive Solvents. U. S. Patent 4,828,029, May

22. Prausnitz, J. M., R. N. Lichtenthaler, and E. Gomes de Azevedo. Molecular Thermodynamics of Fluid-Phase Equilibria. Prentice-Hall, Englewood Cliffs, NJ, 1986. 
23. Cochran, H. D., L. L. Lee, and D. M. Pfund. Application of the Kirkwood-Buff Theory of Solutions to Dilute Supercritical Mixtures. Fluid Phase Equil., v. 34, 1987, p. 219.

24. Pfund, D. M., L. L. Lee, and H. D. Cochran. Application of the Kirkwood-Buff Theory of Solutions to Dilute Supercritical Mixtures. II. The Excluded Volume and Local Composition Models. Fluid Phase Equil., v. 39, 1988, p. 161.

25. McHugh, M. and M. E. Paulaitis. Solid S lubilities of Naphthalene and Biphenyl in Supercritical Carbon Dioxide. J. Chem. Eng. Data, v. 25, 1980, p.326.

26. Orr, F. M. Jr. and M. K. Silva. Effect of Oil Composition on Minimum Miscibility Pressure-.Part 2: Correlation. SPE Reservoir Eng., v. 2, No. 4, November 1987, pp. 479-491.

27. National Institute for Petroleum and Energy Research. Quarterly Technical Report: Dept. of Energy Report No. NIPER-470, v. 2, 1990, pp. 50-57.

28. Huang, Feng-Hsin, Meng-Huill, Lloyd L. Lee, Kenneth E. Starling, and Frank T. H. Chung. An Accurate Equation of State for Carbon Dioxide. J. Chem. Engineering of Japan, v. 18 no. 6, 1985, pp. 490-496.

29. Redlich, Otto, and J. N. S. Kwong. On the Thermodynamics of Solutions. V. On Equation of State. Fugacities of Gaseous Solutions. Chemical Reviews, v. 44, 1949, pp. 233-244.

30. Somayajulu, G. Raam. Estimation Procedures for Critical Constants. J. Chem. Eng. Data, v. 34, No. 1, 1989, pp. 106-120.

31. Christiansen, Richard L. Method of Determining the Minimum Level of Enrichment For a iniscible Gas Flood. U.S. Patent 4,610,160, September 1986.

32. Llave, Feliciano M. and Frank T. H. Chung. The Use of Entrainers for Improving Gas Mobility Control and Displacement Efficiency. Dept. of Energy Report No. NIPER-362, November 1988, 38 pp. NTIS Order No. DE89000704.

33. Llave, Feliciano M. Development of Technology for Entrainer-Enhanced CO2 Flooding. Dept. of Energy Report No. NIPER-445, September 1989, 24 pp. 

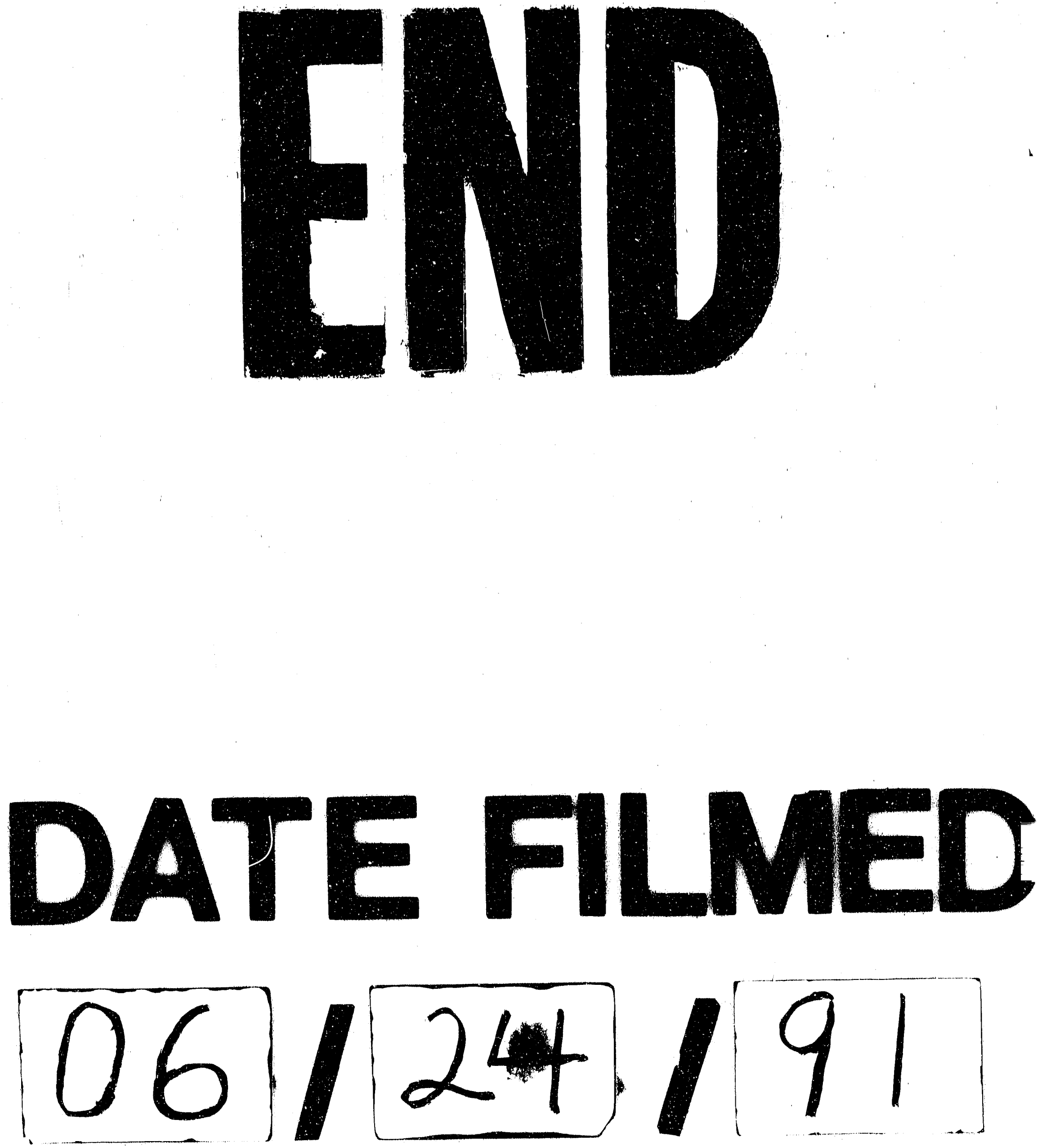
